\title{
Articulação da geometria euclidiana plana e da álgebra no estudo de geometria analítica com o Grafeq
}

\author{
Marilena Bittar \\ Professora, UFMS \\ marilenabittar@gmail.com
}

\section{Adnilson Ferreira de Paula}

Professor, Instituto Federal de Mato Grosso do Sul

adnilson_fer@hotmail.com

\begin{abstract}
Resumo
Nossa pesquisa investigou a mobilização e a articulação de conceitos de Geometria Plana e de Álgebra no estudo da Geometria Analítica por alunos de uma Licenciatura em Matemática. Foi realizado um projeto de extensão com duração de dois meses, com proposição de atividades que envolviam o uso do papel e lápis e do software Grafeq por esse favorecer a articulação entre a Geometria e a Álgebra. A elaboração das situações propostas buscou apoio na Teoria de Registros de Representação Semiótica e sua realização foi proposta na perspectiva da abordagem construcionista. A elaboração das atividades e a análise dos dados tomaram como referência a engenharia didática. Nesse artigo apresentamos dados de uma participante da pesquisa. Os resultados evidenciaram dificuldades da acadêmica tanto no tratamento quanto na conversão entre registros e isso ocorreu para quase todos os conceitos trabalhados. As retroações oferecidas pelo software foram fundamentais para a evolução das estratégias dos acadêmicos.
\end{abstract}

Palavras-chave: Registros de Representação Semiótica. Construcionismo. Espiral de Aprendizagem.

\section{Articulation of plane geometry and algebra on the study of analytic geometry with Grafeq}

\begin{abstract}
Our research investigated students' mobilization of and articulation between concepts of plane geometry and algebra in analytic geometry courses in a mathematics teacher-training program. A project, lasting two months, with activities involving the use of paper and pencil and Grafeq software to encourage reconciliation between geometry and algebra was carried out. The situations were proposed on the basis of the Theory of Semiotic Representation Records and with constructionist approach. The activities were built and data was analyzed taking as theoretical framework the Didactic Engineering, The results showed students' difficulties on treating as well as on converting records for almost all concepts worked. The feedbacks provided by Grafeq software were keys to the students' development of strategies. In this paper, we present data from one of the participants.
\end{abstract}

Keywords: Semiotic Representation Records. Constructionism. Spiral Learning approach. 


\section{Introdução}

A geometria analítica é um campo da matemática que articula dois outros: a geometria e a álgebra.

A Geometria Analítica baseia-se na ideia de representar os pontos da reta por números reais, os pontos do plano por pares ordenados de números reais. [...] Isto permite tratar algebricamente muitas questões geométricas e, reciprocamente, interpretar de forma geométrica certas situações algébricas. (LIMA, 2010, p.1)

As Orientações Curriculares para o ensino médio indicam que o professor deve explorar o estudo de figuras geométricas por meio de equações e, da mesma forma, o estudo de equações deve ser relacionado às figuras geométricas. Nesse sentido, as Orientações Educacionais Complementares aos Parâmetros Curriculares Nacionais para o Ensino Médio (BRASIL, 2006) ressaltam que compreender as ferramentas matemáticas oferecidas pela geometria analítica é mais importante do que memorizar diferentes equações para um mesmo ente geométrico.

Goulart (2009) afirma que alunos do ensino médio têm dificuldades em entender que uma equação indica um conjunto de pontos cujas coordenadas atendem certas condições algébricas. Assim, compreender a equação $x+y=4$ significa compreender, entre outras coisas, que um par ordenado do plano pertence ao gráfico dessa equação se ele satisfaz equação. Nesse sentido, Santos (2002, p. 96) constatou que "a aquisição dos saberes relacionados aos coeficientes da equação $y=a x+b$ por meio da articulação dos registros gráfico e algébrico da função afim, em geral resistente ao ensino usual, é, no entanto, susceptível de saltos qualitativos importantes via a interação aluno/software".

Esse tipo de problema também está no centro da pesquisa de Fonte (2010) que investigou a compreensão de alunos do ensino médio dos Estados Unidos relacionadas ao conceito de solução de uma equação, mais particularmente a dificuldade dos alunos em identificar que as coordenadas de qualquer ponto sobre uma reta satisfazem a equação da reta. Acreditamos que essa dificuldade é provocada pelo ensino que usualmente parte da álgebra para a geometria, ou seja, em geral é dada a lei de formação de uma função e o aluno deve identificar seu gráfico, e não o contrário, trabalhando-se somente um sentido da conversão (DUVAL, 2003).

Dallemole at al. (2011) investigaram dificuldades de alunos de uma licenciatura em matemática na conversão dos registros de representação semiótica (DUVAL, 2003) em conteúdos de geometria analítica, especialmente àqueles relacionados à 
circunferência. Verificou-se que as dificuldades mais resistentes dos acadêmicos eram em atividades que exigiam conversões entre os registros da língua natural e o algébrico e do registro de representação gráfica para o registro algébrico. Esses resultados coadunam tanto com os encontrados por Fonte (2010) quanto com aqueles encontrados por Maia (2007) que investigou como os alunos percebiam as consequências das mudanças realizadas na escrita algébrica de uma função do $2^{\circ}$ grau sobre seu gráfico e vice-versa. Essa autora propôs o uso do Winplot para a realização das atividades e pode verificar que esse uso contribuiu com a melhoria da aprendizagem dos alunos.

Richit (2005) discutiu como trabalhar com projetos em geometria analítica usando um software de geometria dinâmica, com o objetivo de favorecer a formação de futuros professores de Matemática. A autora considerou que em várias atividades desenvolvidas houve "preocupação dos licenciandos com o próprio entendimento dos conceitos e propriedades abordados e com as formas de aplicação prática dos mesmos, como condição necessária à aprendizagem destes". (Richit, 2005, p. 145)

A partir destas e outras leituras, decidimos investigar como alguns conceitos da geometria plana e da álgebra são mobilizados e articulados em estudos da geometria analítica por alunos de uma licenciatura em matemática usando o Software Grafeq $^{1}$, A escolha desse software se deu pelo fato de ele favorecer a realização de atividades que pedem a conversão entre registros de representação semiótica, atividade essencial no processo de apreensão de um conceito (DUVAL, 2003). É importante também ressaltar que nossos sujeitos de pesquisa tinham conhecimento prévio sobre o objeto de estudos e olhamos para a geometria analítica como um campo que trabalha ao mesmo tempo com a álgebra e com a geometria e não como um conjunto de fórmulas.

A seguir discutimos os principais elementos teóricos que nortearam nossa pesquisa e, em seguida, trazemos a análise de alguns dados de uma participante da pesquisa.

\section{A tecnologia e a educação matemática}

Kenski (2003, p. 211) afirma que "o homem transita culturalmente mediado pelas tecnologias que lhes são contemporâneas. Elas transformam suas maneiras de pensar, sentir e agir. Mudam até suas formas de se comunicar e de adquirir conhe-

1. É um software que trabalha tanto conceitos de geometria plana quanto de álgebra, cuja versão shareware pode ser obtida no endereço www.peda.com/grafeq. 
cimentos.". Concordamos com Kenski quando diz que estamos vivendo um novo momento tecnológico, e que a ampliação das possibilidades de comunicação e de informação, por meio de equipamentos como o telefone, a televisão e o computador, altera nossa forma de viver e de aprender. Para além disso, acreditamos que a tecnologia digital pode contribuir para a aprendizagem matemática quando utilizada de forma a permitir a construção do conhecimento na perspectiva piagetiana. Buscamos investigar contribuições do software Grafeq para um ensino de geometria analítica que favoreça articulações entre Álgebra e Geometria Plana. Para isso recorremos a Papert (2008), que discute o instrucionismo e o construcionismo, e a Valente (2005), que apresenta a espiral de aprendizagem.

\section{Instrucionismo, construcionismo e a espiral de aprendizagem}

Tanto o instrucionismo quanto o construcionismo discutem a relação professor, aluno e saber mediada pelo uso das tecnologias da informação e comunicação, porém, enquanto no instrucionismo o computador é visto como uma máquina de ensinar, no construcionismo o computador é uma ferramenta que propicia ao aluno a construção do seu conhecimento.

O instrucionismo caracteriza-se por experiências educacionais que têm por objetivo a transmissão do conhecimento. Nessa abordagem o aluno recebe as informações do software em forma de questões e as retornam com uma resposta. Nesses casos o software não evidencia o pensamento desenvolvido pelo aluno ao responder àquela questão. O computador simplesmente fornece um "certo" ou "errado". Em geral se a resposta estiver correta, um novo nível de atividades, mais difícil, é disponibilizado ao aluno.

$\mathrm{Na}$ abordagem construcionista, ao contrário da abordagem instrucionista, o computador é usado visando levar o aluno a refletir, compreender e elaborar novas estratégias a partir de um possível "erro". Assim, a abordagem da utilização do computador elaborada por Papert (2008), chamada de construcionista, favorece a construção do conhecimento dando ênfase à aprendizagem.

Para melhor compreender a abordagem construcionista, Valente (2005) desenvolveu o ciclo de ações: descrição-execução-reflexão-depuração (figura 1). 
Figura 1: Abordagem construcionista de ensino.

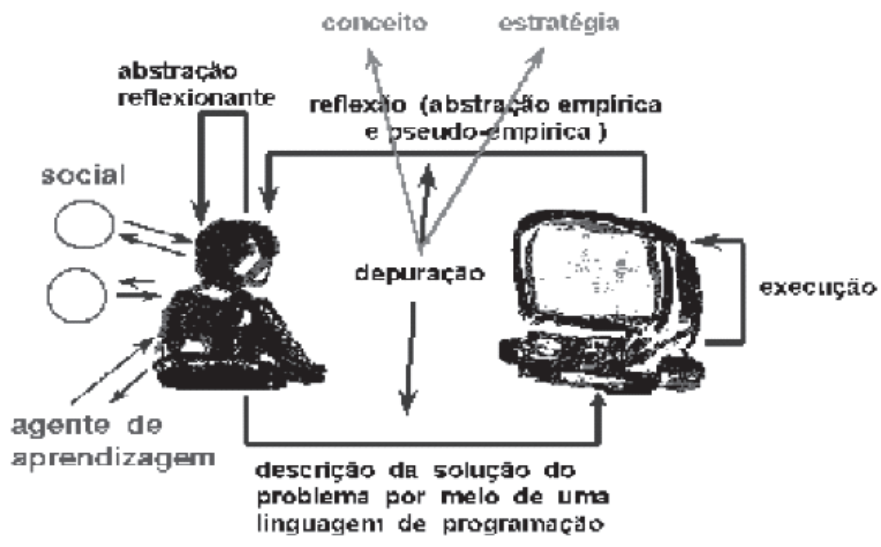

Fonte: VALENTE, 2005, p. 66.

Ao receber um problema, o aluno elabora uma estratégia de solução que deve ser descrita, em linguagem computacional, ao software (descrição). Ao digitar uma relação algébrica e clicar em Enter tem-se a execução das operações enviadas pelo usuário que, ao analisar o que o software lhe devolve, deve concluir sobre a validade (ou não) de sua ação. Podemos aqui observar, claramente, a diferença entre a abordagem instrucionista e a construcionista. Ao receber a retroação do software, o aluno tem a oportunidade de avaliar, interpretar e refletir sobre os conceitos envolvidos e sobre a estratégia utilizada fazendo um paralelo com o resultado apresentado pelo software (reflexão). Nesse momento podem ocorrer abstrações empíricas, pseudo-empíricas e/ou reflexionantes:

[...] a abstração empírica é a mais simples, permitindo ao aprendiz extrair informações do objeto ou das ações sobre o objeto [...] a abstração pseudo-empírica permite ao aprendiz deduzir algum conhecimento de sua ação sobre o objeto. [...] mudanças conceituais e construção de novos conhecimentos são frutos da abstração reflexionante. (VALENTE, 2005, p. 68)

Após a descrição e a execução podem ocorrer duas situações: a retroação oferecida pelo software pode estar de acordo com o esperado, ou, o aluno percebe que houve algum erro de descrição. No primeiro caso o processo é encerrado. No segundo caso, ao notar que sua estratégia não foi adequada para a solução do problema, o aluno evolui para a depuração, passando por abstrações empíricas, pseudo-empíricas ou 
reflexionantes. Na depuração, deve-se considerar os conceitos e as estratégias matemáticas utilizadas anteriormente, descobrir possíveis erros e, a partir deles, melhorar ou substituir um pensamento equivocado, realizando assim, uma nova descrição e, consequente, nova execução, reflexão e depuração incorporando novos elementos à sua à estrutura cognitiva caracterizando assim a espiral de aprendizagem. Esse processo continua até que o aluno fique satisfeito com a resposta oferecida pelo software.

Defendemos o uso dessa abordagem por proporcionar momentos de reflexão ao aluno, pois nessa perspectiva é preciso que o discente descreva de forma organizada, no software, seus conhecimentos. Enfim, na abordagem construcionista deve sempre haver a possibilidade de o aluno questionar e ser questionado, de produzir conhecimento e não simplesmente receber informações. O foco, nessa abordagem, é a aprendizagem e não o uso do computador.

\section{Desenvolvimento das atividades com os acadêmicos}

Desenvolvemos um projeto de extensão nos meses de maio e junho de 2011, com seis sessões de duas horas. Para a elaboração das atividades nos apoiamos na teoria de registros de representação semiótica (DUVAL, 2003), buscando propor situações que favorecessem conversões entre os registros gráfico (desenho com os eixos cartesianos), algébrico (escrita algébrica de funções, equações e inequações) e o das coordenadas (representação algébrica de um ponto). A metodologia de pesquisa adotada foi a engenharia didática que consiste em "[..] um esquema experimental baseado em 'realizações didáticas' na sala de aula, isto é, na concepção, na realização, na observação e na análise de uma sequência de ensino". (ARTIGUE, 1996, p. 196). A engenharia didática prevê a realização da pesquisa em quatro fases: análise preliminar; elaboração da sequência didática e análise a priori; realização da sequência didática, e, finalmente a análise $a$ posteriori. A análise de dados é feita comparando a análise a priori com a análise a posteriori, que é uma característica marcante dessa metodologia da engenharia didática ${ }^{2}$.

Foram propostas 16 atividades, desenvolvidas em seis sessões de, em média, duas horas de duração, com um total de 14 horas. Nas primeiras os alunos deveriam mobilizar propriedades relacionadas às funções afim e quadrática, e às equações da circunferência, da elipse e da hipérbole. Já nas últimas atividades elaboramos situações, no papel e lápis ou software, que oportunizassem a mobilização e a articulação de conceitos de geometria plana e de álgebra atribuindo significado à geometria analítica.

2. Não discutiremos mais detalhes da engenharia didática nesse texto devido à extensão do mesmo, porém, mais informações podem ser encontradas em (DE PAULA, 2011). 
Analisamos as produções de 4 acadêmicos (Carlos, Nayara, Fabiana e Edna ${ }^{3}$ ) no software, além de debates registrados em áudio. Nesse texto damos ênfase ao trabalho desenvolvido por Edna e trazemos análises a posteriori referentes a uma dessas atividades (ver apêndice), a 12 , buscando estabelecer relações com as referências teóricas.

\section{Atividade 12}

Utilizando o Grafeq construa o desenho apresentado a seguir. Justifique sua construção:

Figura 2: Desenho a ser reproduzido na tela do grafeq

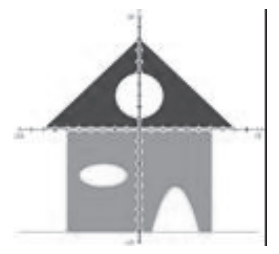

Nessa atividade a intenção era oportunizar a mobilização e articulação de conceitos algébricos e geométricos de ponto, reta, circunferência, elipse, parábola e sistemas de inequações, conceitos estes trabalhados em atividades anteriores. Para reproduzir na tela do Grafeq o desenho da casa é necessário usar relações algébricas, ou seja, deve-se efetuar a conversão do registro da figura (o desenho foi dado em papel) para o algébrico. E isso deve ser feito de modo a obter o registro geométrico correspondente - figura reproduzida na tela do computador deve ser semelhante à fornecida no papel.

Para efetuar a descrição do problema, Edna iniciou a resolução do problema convertendo para o registro algébrico o desenho da parte inferior da casa (região interna ao retângulo):

Figura 03: Vídeo - representações algébrica e gráfica da parte inferior da casa
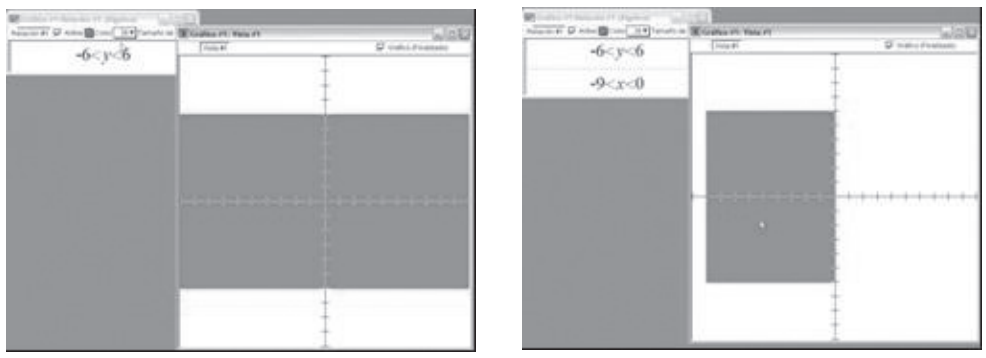

3. Nomes fictícios 
O software executa os comandos e quando Edna percebe, por meio de uma reflexão empírica (baseada no que o Grafeq exibe), que não era essa a região desejada, altera a relação algébrica inicial efetuando um tratamento. Vemos, portanto, que o uso do software leva o sujeito a refletir sobre a conversão entre registros realizada pelo software para tentar, então, descobrir qual tratamento deve ser realizado para obter a figura desejada. Assim sendo, Edna trabalha com o registro algébrico com o objetivo de obter a representação geométrica desejada.

Figura 04: Vídeo - ação da aluna após retroação do software
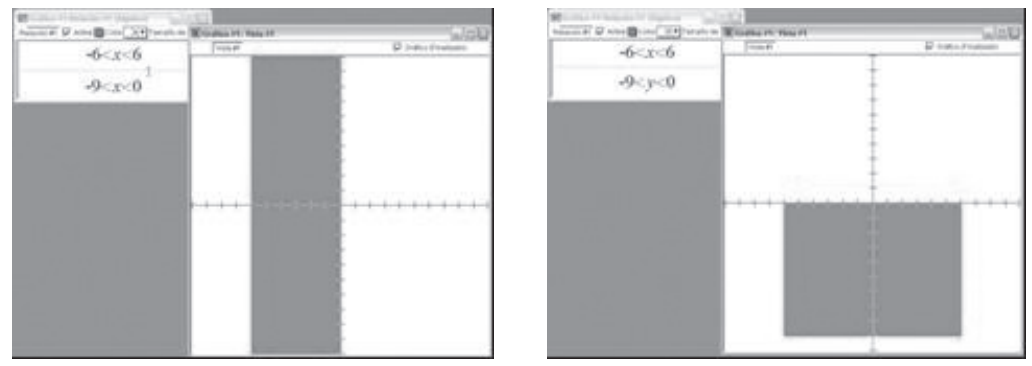

Inicialmente Edna inverte as condições de $\mathrm{x}$ e de $\mathrm{y}$ para que um ponto $\mathrm{P}(\mathrm{x}, \mathrm{y})$ pertença à região e em seguida, quando tenta alterar a relação algébrica, não consegue de imediato o resultado esperado. Nesse caso, ela realizou uma série de depurações nas relações algébricas que alterou, entretanto, é provável que tenha se restringido a abstrações empíricas, pois buscou representar no software aquilo que observou no papel, isto é, uma região retangular na parte inferior do plano cartesiano tendo o eixo y como eixo de simetria. Em seguida, Edna fez uma série de plotagens tentando representar algebricamente a região externa à parábola. Segue um diálogo, ocorrido entre Edna e Nayara, que evidencia a reflexão realizada por elas a partir da imagem exibida no software.

Edna: Nayara... Como que faz isso aqui... Quando aqui óh tipo o vértice tem que ficar aqui, né? Então essa parábola é o que... $\mathrm{y}=-\mathrm{x}^{2}$

Nayara: isso.... - 5

Edna: então eu coloquei menos 5, vai dar aqui no y

Nayara: então, aqui não é?...só que aí....

Edna: mas eu não quero ela aí... eu quero ela no ponto $(3,-5)$

Nayara: então você vai colocar entre parênteses né?, aí + 3 pra lá, aí vai ser menos 3

Edna: não, mais 3 mesmo, porque é três positivo, não é? 
Figura 05: Vídeo - dificuldade para descrever algebricamente a função quadrática
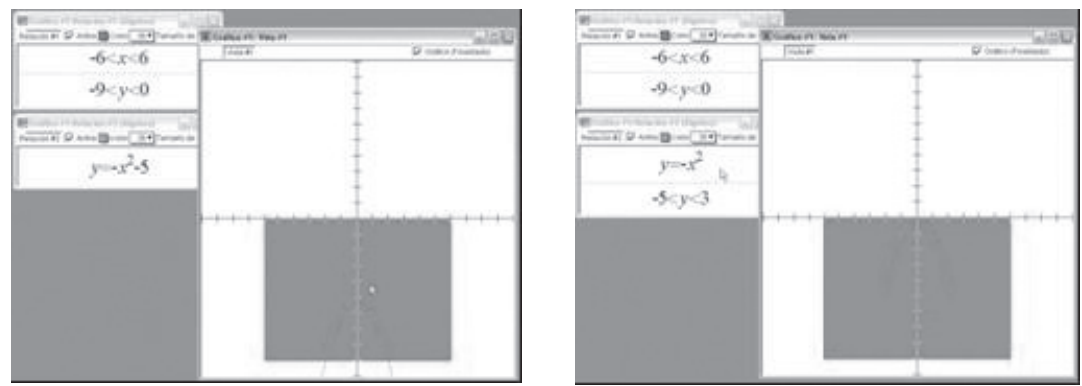

Após receberem a retroação do software, Edna e Nayara parecem começar a refletir sobre propriedades algébricas da função quadrática, contudo tiveram dificuldade em descrever algebricamente a função quadrática que representa o gráfico que procuram. Tentam, entre outros, representar o gráfico de uma parábola com vértice no ponto $\mathrm{P}(3,-5)$ utilizando a inequação $-5<\mathrm{y}<3$. Nesse momento parecem ter realizado uma abstração pseudo-empírica, pois conseguem observar, com a retroação do software, que o vértice da parábola desenhada não está no ponto de coordenadas $\mathrm{P}(3,-5)$. A dificuldade em obter a figura desejada é devida a não articulação entre a álgebra e a geometria, pois elas têm dificuldades em trabalhar a relação algébrica para obter a figura desejada. Não conseguindo realizar as depurações necessárias para representar a região externa à parábola, Edna desiste de construir essa parte do desenho e tenta representar algebricamente a região interna ao triângulo (região superior da casa). Inicialmente, faz a descrição algébrica do gráfico de uma função afim que limita a região (figura 6).

Figura 06: Vídeo - Tentativas de construção da parte superior da casa
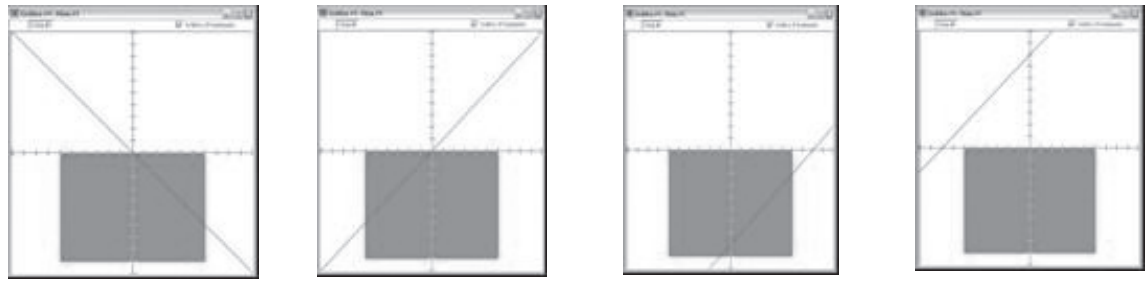

Edna plotou as relações $\mathrm{y}=-\mathrm{x}, \mathrm{y}=\mathrm{x}, \mathrm{y}=\mathrm{x}-8$ e $\mathrm{y}=\mathrm{x}+8$ nessa ordem. Acreditamos que na passagem de uma relação para outra, a acadêmica tenha vivenciado os processos de descrição $(\mathrm{y}=-\mathrm{x})$, execução, reflexão (ocorre a partir dos 
resultados observados por Edna no software e, dessa forma pode ser empírica ou pseudo-empírica) e depuração (ao observar que y = -x não representou o gráfico que queria, considerou possíveis erros e fez nova descrição, isto é y =x). Em seguida passa a trabalhar com inequações e consegue representar algebricamente a região desejada, conseguindo, para essa parte da atividade, realizar os tratamentos algébricos necessários para obter a representação geométrica desejada.

Em relação à região externa à elipse, Edna percebe que precisa transladar a curva, porém não sabe que transformação (tratamento) deve usar na relação algébrica da elipse e então pede ajuda a Carlos:

Carlos: como que eu faço pra transladar ela no eixo?..... eu sei que ela vai uma, duas, três para a esquerda... então eu somo mais três no quadrado, no x, mais 3 ... aí eu quero transladar para baixo, soma no eixo y... aí vai transladar. Edna: sério cara? Então você soma!

Carlos: é

Fabiana: você é bom em transladar hein, Carlos, rsrsrs.

Carlos: é eu translado.

Com essa ajuda, Edna obtém a figura desejada, porém tem dificuldade para articular o conceito de inequações e de sistemas de inequações com a representação geométrica que deseja obter:

Edna: aí você colocou maior, Carlos, por quê?

Carlos: porque eu quero o interior, porque quero maior que ele... e não ele

\section{Figura 07: Vídeo - Construção da região externa a elipse}
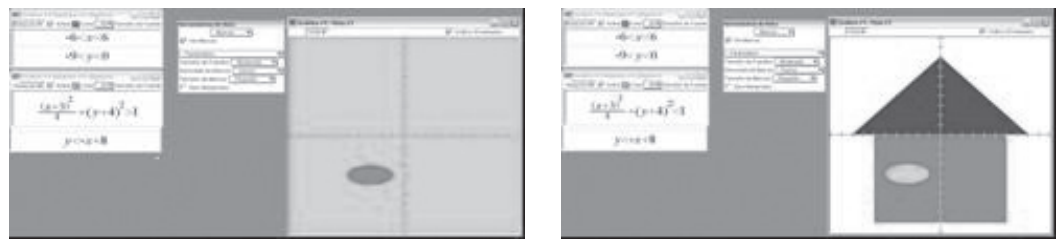

Edna continuou tentando resolver a atividade e conversando com ela um pouco mais tarde, percebemos que suas dúvidas sobre como trabalhar com a parte algébrica para obter a representação geométrica desejada continuavam, porém, algumas relações começavam a ser estabelecidas, como podemos observar no excerto a seguir acompanhado da figura 8 . 
Pesquisador: tenta pensar o que significa menor, o que significa igual, o que significa maior.

Edna: então.... Maior é o que tá pra fora... Maior do que isso aqui... Menor é o que tá dentro.

Pesquisador: tenta cada um deles pra ver o que acontece

Edna: não eu já fiz maior.....

Edna: aí óh, maior é o que tá fora da bolinha...

Pesquisador: tá

Edna: aí menor é ele pintado

$[\ldots]$

Nayara: é que você vai desenhar uma coisa furada, entendeu?... você vai desenhar tipo um quadradinho, um retângulo furado no meio, entendeu? Por isso que tem que ser... tenta desenhar agora.

Figura 08: Vídeo - Região externa a elipse e interna ao retângulo

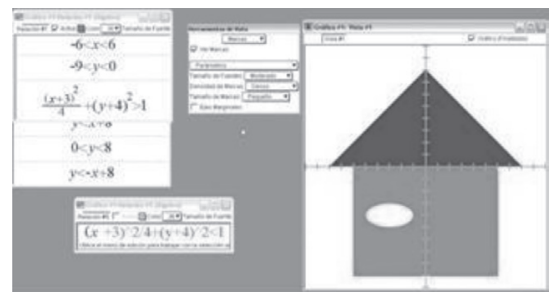

E finalmente, ao contemplar um pouco mais sua própria produção, Edna parece começar a compreender melhor a articulação entre as relações algébricas (dadas pelo registro algébrico) e o gráfico obtido, como observamos no próximo excerto:

Pesquisador: vamos entender agora, Edna. Porque que ficou branco?

Edna: porque eu já tenho essas duas condições antes. $\mathrm{x}$ tem que tá aqui e aqui e y aqui .... aí que que isso quer dizer então em uma relação, eu vou continuar trabalhando nisso aqui só que..... vai ser.... ah!!!!!!!!!!! seria assim óh... eu tenho aqui o quadrado.... tá todo pintado né? Aí essa parte maior.... então o maior dele só vai dentro do quadrado (referindo-se à parte do quadrado e seu interior, retirando-se a elipse e seu interior).

Nesse caso é provável que Edna tenha migrado de uma abstração empírica para uma pseudo-empírica ao falar de sistemas de inequações. Após várias descrições e execuções realizadas pelo software, a acadêmica vai depurando suas ideias 
até começar a compreender a retroação oferecida pelo Grafeq. Notemos que Edna diz "ah! seria assim óh" somente depois de ter o resultado pronto no software. Isso mostra que a conclusão da acadêmica estava baseada no observável.

Procurando melhor compreender questionamos Edna sobre o que entendeu da retroação após execução do software.

Edna: só que eu quero ela maior... o maior dela vamos supor.. no gráfico ia ser tudo né? Aí só ia ficar isso aqui branco... mas como eu to dentro do quadrado, só vai ser até aqui o maior dela. Será que é isso?

Pesquisador: ok, isso seria um sistema de inequações?

Edna: é.... você entendeu o que eu quero dizer?

Pesquisador: sim entendi... correto.

Edna: o maior dela só é dentro disso aqui óh

Assim, pode-se confirmar que Edna passa a melhor compreender o resultado apresentado pelo software. Após descrição e execução do problema, ela não se restringe a abstrações empíricas, mas faz uso, simultaneamente, das abstrações empíricas e pseudo-empíricas, pois deduz, a partir de sua ação sobre o software, o conceito de sistemas de inequações e suas relações com a região do plano a ser obtida.

Depois de alguns minutos, Edna continua apresentando dificuldades para encontrar a relação algébrica que representa as regiões externas à circunferência e à parábola e pede ajuda a Carlos.

Edna: ah Carlos vem aqui me ajudar se não eu vou demorar mil anos

Nayara: vai, qual que você tá fazendo?

Edna: a bolinha ali de cima

Carlos: analisa só a bolinha. Ela tem raio quantos?

Edna: ah ela tem raio 2

Carlos: qual que é a fórmula da circunferência?

Ao mesmo tempo em que Carlos dá instruções, discute alguns conceitos com Edna, dessa forma os dois aproveitam as retroações do software fazendo as devidas depurações. Assim, Edna, com a ajuda de Carlos conclui a atividade depois de representar de forma satisfatória as regiões externas à circunferência e à parábola. 


\section{Considerações Finais}

Partindo de alguns estudos sobre a geometria analítica e apoiados em Papert (2008), Valente (2005) e Duval (2003) procuramos compreender como futuros professores de matemática mobilizam e articulam conceitos de álgebra e geometria plana em estudos da geometria analítica. A mobilização e a articulação entre a geometria e a álgebra foram favorecidas, em nossa sequência, pelas atividades propostas no Grafeq.

Nesse texto, discutimos os dados relativos à Edna, uma das participantes de nossa pesquisa, e, dentre as 16 atividades realizadas por ela, apresentamos e discutimos somente uma delas, por ser representativa de seus resultados. A atividade consistia em repetir na tela do Grafeq um desenho dado no papel.

Edna teve a oportunidade de relacionar álgebra e geometria plana simultaneamente, pois para refazer o desenho na tela do Grafeq, era necessário utilizar relações algébricas. Além disso, quando o resultado obtido não era o desejado, ela devia efetuar tratamentos na tentativa de chegar à solução esperada. Nesse momento, quando o software devolvia uma imagem, correspondente à expressão algébrica dada, à Edna, ela devia tentar entender o que "havia" em sua expressão que não correspondia ao desejado. Podemos então dizer que ocorria uma conversão entre registros, não escrita, porém mental, uma vez que a acadêmica fazia a transformação na expressão algébrica e a mudança na figura era efetuada pelo software, porém "imaginada" por Edna.

Percebemos que Edna, tendo parte do conhecimento necessário para a realização da atividade, conseguiu, por meio de abstrações empíricas e pseudo-empíricas, realizar depurações que a levou a organização das ideias centrais de um conceito. É válido considerar que não identificamos abstrações reflexionantes na ação da aluna, isto é, reflexões dissociadas das retroações do Grafeq, entretanto, as abstrações empíricas e pseudo-empíricas, conseguidas por meio do software, foram suficientes para levar Edna a melhor compreensão de ao menos parte dos conhecimentos abordados.

\section{Referências}

ARTIGUE, M.. Ingénierie didactique. Recherches en didactique des mathématiques, Grenoble, France: vol.9, no 3, 1988.

\section{BRASIL. Orientações Curriculares para o Ensino Médio: ciências da natureza, matemática e suas tecnologias. Brasília: MEC, 2006.}


BRASIL. Orientações Educacionais Complementares aos Parâmetros Curriculares Nacionais. Ciência da natureza, matemática e suas tecnologias. Brasília, Mec, 2006.

DALLEMOLE, J. J.; GROENWALD, C. L. O. ; RUIZ, L. M. Os registros de representação semiótica no estudo da circunferência com enfoque na geometria analítica. Boletim Gepem, v. 59, p. 95-112, 2011.

DE PAULA, A. F.. Mobilização e articulação de conceitos de geometria plana e de álgebra em estudos da geometria analítica. Dissertação de Mestrado em educação Matemática. Campo Grande, Universidade Federal de Mato Grosso do Sul, 2011.

DUVAL, R.. Registros de Representação Semióticas e funcionamento cognitivo da compreensão em matemática. In: MACHADO, Silvia Dias Alcântara. (Org.). Aprendizagem em Matemática: Registro de Representação Semiótica. 1 ed. São Paulo: Papirus, 2003, p. 11- 33.

FONTE, R. B. Discutindo as dificuldades dos alunos na visualização gráfica da solução da equação de uma reta. Boletim Gepem, v. 56, p. 15-29, 2010

GOULART, J. B.. O estudo da equação $\mathbf{A x ^ { 2 } + B y ^ { 2 } + C x y + D x + E y + F = 0 : ~ U t i l i z a n d o ~}$ o software Grafeq - uma proposta para o Ensino Médio. Dissertação de mestrado profissionalizante no Ensino de Matemática. Porto Alegre, Universidade Federal do Rio Grande do Sul, 2009.

KENSKI, V. M.. Tecnologias e ensino presencial e a distância. São Paulo: Papirus, 2003.

LIMA, E. L.. Geometria Analítica e Álgebra Linear. Rio de Janeiro, Impa, 2010.

MAIA, D.. Função quadrática: um estudo computacional. Dissertação de mestrado em Educação Matemática, São Paulo, Pontifícia Universidade Católica, 2007.

PAPERT, S.. A Máquina das Crianças: repensando a escola na era da informática. Porto Alegre, Artmed, 2008.

RICHIT, A.. Projetos em geometria analítica usando software de geometria dinâmica: repensando a formação inicial docente em matemática. Dissertação de Mestrado em Educação Matemática. São Paulo, UNESP - Rio Claro, 2005. 
SANTOS, E. P.. Função Afim: a articulação entre os registros gráfico e algébrico com auxílio de um software educativo. Dissertação de Mestrado em Educação Matemática. São Paulo, Pontifícia Universidade Católica, 2002.

VALENTE, J. A.. O ciclo de ações e Espiral de Aprendizagem. Disponível em: $<$ http://pan.nied.unicamp.br/ lia/ciclo_e_espiral.pdf >. Acesso em: 27 mar. 2012.

Submetido em dezembro de 2012. Aprovado em março de 2013.

\section{APÊNDICE}

\section{SEQUÊNCIA DE ATIVIDADES UTILIZADAS NA PESQUISA}

01. O ponto P1 $(-1,5)$ faz parte do conjunto de pontos que satisfazem a relação y + $\mathrm{x}=3$ ? Justifique sua resposta.

02. Construa, com auxílio de papel e lápis, o gráfico da função $y=2 x+4$. Descreva o processo de construção.

03. Reproduza a figura abaixo no Grafeq. Justifique sua construção.

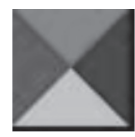

04. Reproduza a figura abaixo no Grafeq. Descreva o processo de construção.

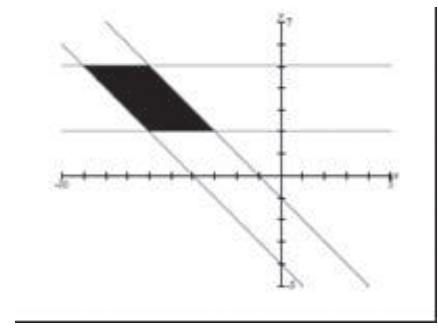

05. Construa no Grafeq a região do plano delimitada pelos gráficos das funções y= $3 x+3, y=-x+3$ e $y=x+2$. Descreva o processo de construção da região. 
06. Construa no Grafeq a região do plano delimitada pelas relações $\mathrm{x}-\mathrm{y}=-5, \mathrm{x}+$ $y=5, x+y=5$ e $x+y=-5$. Descreva o processo de construção da região.

07. Determine a posição relativa do ponto $\mathrm{P} 2(-1,-2)$ em relação ao gráfico definido pela equação $\mathrm{x}^{2}+\mathrm{y}^{2}=9$ ? Justifique sua resposta.

08. Utilizando o Grafeq construa a região apresentada abaixo. Justifique sua construção:

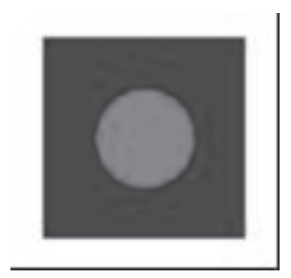

09. O ponto $\mathrm{P} 1(1,2)$ pertence ao conjunto de pontos que satisfaz a relação $\mathrm{y}=\mathrm{x}^{2}$ - 4? Justifique sua resposta.

10. Construa no Grafeq o conjunto de pontos representado pela figura abaixo. Justifique cada etapa da construção.

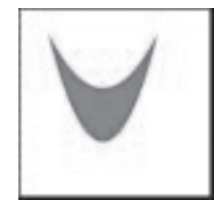

11. Observe o conjunto de pontos (x, y) e esboce-os no Grafeq.

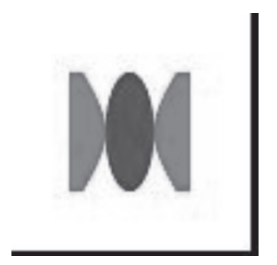

12. Utilizando o Grafeq construa o desenho apresentado abaixo. Justifique sua construção:

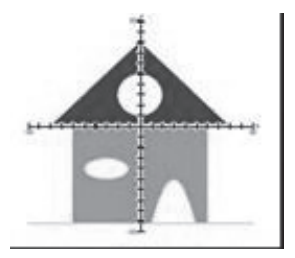


13. Construa no Grafeq a bandeira do Brasil. Justifique cada uma das construções. 14. Esboce, no papel e no mesmo plano cartesiano, as regiões delimitadas pelas relações apresentadas a seguir. Justifique suas construções.

$$
(\mathrm{x}-4)^{2}+\mathrm{y}^{2}<4 ;(\mathrm{x}+4)^{2}+\mathrm{y}^{2}<4 ; \quad\left\{\begin{array}{c}
x^{2}-y^{2}<1 \\
-2<y<2
\end{array} ;\left\{\begin{array}{c}
-6<x<6 \\
2<y<4
\end{array}\right.\right.
$$

15. Esboce, no papel e no mesmo plano cartesiano, as regiões delimitadas pelas relações apresentadas a seguir. Justifique suas construções.

$\left\{\begin{array}{c}-3<x<10 \\ 2<y<3\end{array} ;\left\{\begin{array}{c}5<x<\frac{-y+23}{2} \\ 3<y<7\end{array} ;(y-5)^{2} / 4+x^{2} / 25<1 ;(x-7)^{2}+(y-1)^{2}<1 ;(x-1)^{2}+(y-1)^{2}<1\right.\right.$.

16. Esboce, no papel e lápis, um desenho qualquer e, em seguida reproduza-o na tela do Grafeq. 